\title{
“Eu fiz meu game”: um framework para desenvolvimento de jogos por crianças
}

\author{
Title: "I made my game": a framework for the design of games by children
}

\author{
Adriana Gomes Alves \\ Univali-Universidade do Vale do \\ Itajai \\ adriana.alves@univali.br
}

\author{
Regina Célia Linhares Hotins \\ Univali-Universidade do Vale do \\ Itajai \\ reginalh@univali.br
}

\author{
André Luis Alice Raabe \\ Univali-Universidade do Vale \\ do Itajai \\ raabe@univali.br
}

\begin{abstract}
Resumo
Discute-se neste artigo o framework "Eu fiz meu game" o qual foi construído para o desenvolvimento da criatividade por meio de criação de jogos digitais por e com crianças no contexto de inclusão escolar. O framework emprega abordagens do design participativo propiciando o protagonismo da criança em todas as atividades, por meio de técnicas diferenciadas como cartões de ideias, w-questions cards, brainstorm, desenho, design experimental, implementação, dentre outras. A metodologia de pesquisa foi o Design-based Research, abordagem que considera profunda colaboração entre pesquisadores e participantes no sentido de alcançar os objetivos teóricos e práticos da investigação. Participaram da pesquisa quatro crianças de nove anos de idade-dentre as quais duas com deficiência intelectual -, em parceria com pesquisadoras e acadêmicos das áreas da Educação, Ciência da Computação e Design de Jogos. A pesquisa partiu da compreensão de que a participação das crianças, notadamente as com deficiência intelectual, na construção dos jogos, e não somente no jogar, possibilita o desenvolvimento da imaginação e criatividade na infância e consequentemente das funções psicológicas superiores, necessárias ao pensamento complexo, aliando os conceitos do design participativo às concepções de aprendizagem e desenvolvimento do campo da psicologia histórico-cultural desenvolvida por Vigotski. O estudo evidenciou que a produção de um jogo digital sustentado em um framework colaborativo favoreceu a aprendizagem das crianças, especialmente aquelas com deficiência intelectual, as quais viveram a experiência de interação e de criação em atividades de jogos, ampliando seu universo de imaginação e materialização de sua criatividade.
\end{abstract}

Palavras-Chave: Inclusão escolar; Framework; Práticas inovadoras; Jogos digitais; Educação.

\begin{abstract}
This paper discusses the framework "I made my game" which was defined for the development of creativity through digital games creation for and with children in the context of school inclusion. The framework applies participatory design approaches, promoting the child's protagonism in all activities, through differentiated techniques such as idea cards, w-questions cards, brainstorm, drawing, experimental design, implementation, among others. The research methodology was the Design-based Research, an approach that considers deep collaboration between researchers and participants to achieve the theoretical and practical objectives of the research. The research participants were four nine-years-old students - including two with intellectual disabilities - in collaboration with researchers and undergraduate students from the areas of education, computer science and game design. The research stem from the understanding that the participation of children, especially those with intellectual disabilities, in the construction of games, not only in play, allows the development of imagination and creativity in childhood and consequently of their higher psychological functions necessary for complex thinking, combining the concepts of participatory design with the conceptions of learning and development of the field of historical-cultural psychology developed by Vigotski. The study showed that the production of a digital game based on a collaborative framework favored children's learning, especially those with intellectual disabilities, who experienced the interaction and the creation in games activities, expanding their universe of imagination and materialization of their creativity.
\end{abstract}

Keywords: School inclusion; Framework; Innovative practices; Digital games; Education.

Cite as: Alves, A.G., Hostins, R.C.L. \& Raabe, A.L.A. (2019). "I made my game”: a framework for the design of games by children (Eu fiz meu game”: um framework para desenvolvimento de jogos por crianças). Brazilian Journal of Computers in Education (Revista Brasileira de Informática na Educação - RBIE), 27(2), 218-238. DOI: 10.5753/RBIE.2019.27.02.218 


\section{Introdução}

A criação de jogos digitais por crianças é defendida por diferentes autores como a possibilidade de trabalhar conceitos e estratégias complexos e, para além dos conhecimentos da tecnologia, propiciar a interação entre diferentes áreas do conhecimento. De Paula, Valente e Hildebrand (2016) acreditam que o jogo digital como uma forma cultural contemporânea, faz parte de um debate atual na educação acerca dos diversos letramentos - imagéticos, sonoros - que os aprendizes devem desenvolver. Li (2014) argumenta que a aprendizagem por meio do design de jogos digitais favorece o desenvolvimento de habilidades como criatividade, comunicação, pensamento crítico, lógica e resolução de problemas, oportunizando, segundo a autora "cultivar habilidades vitais para o Século 21” (Li, 2014, pp. 49, tradução nossa).

Para o desenvolvimento de jogos com e por crianças, encontram-se na literatura propostas metodológicas tais como definem Marchetti e Valente (2015), Moser (2015) e Li (2014). Estes propõem modelos que estabelecem etapas e estratégias para o desenvolvimento de atividades de criação de jogos, evidenciando necessidades específicas, estratégias e abordagens de design. Tomam-se por exemplo as observações de Marchetti e Valente (2015) que identificaram na atividade de programação de jogos um fator limitante à criatividade das crianças, e por isso propõem um processo em que se realiza a transposição de jogos digitais para jogos de cartas e seu retorno ao digital como abordagem pedagógica. Moser (2015), por outro lado, propõe um framework para desenvolvimento de jogos por e com crianças cuja instanciação pode se dar de diferentes formas, incluindo todas as etapas ou algumas delas, conforme os propósitos do educador. Li (2014) nos brinda com um profundo estudo sobre o processo de aprendizagem por meio do game design, propondo um modelo nominado Learner Design Educational Game (LDEG), que visa o desenvolvimento de jogos educativos por estudantes ou adultos aprendizes. Os achados da pesquisadora por meio da aplicação do modelo em diferentes projetos, revelam o potencial do design de jogos como abordagem pedagógica, notadamente na flexibilidade de focar a aprendizagem para qualquer assunto, a diversidade de habilidades demandadas e a adoção do design de jogos como uma ferramenta mental.

Considerando as pesquisas em educação inclusiva, buscou-se investigar o envolvimento de estudantes com deficiência intelectual em projetos de desenvolvimento de tecnologia. Constatase que há um crescente aumento de pesquisas que incluem crianças com deficiências em processos de design, porém ainda com pouco envolvimento ativo dessas (Börjesson, Barendregt, Eriksson, e Torgersson, 2015). Börjesson et. al. (2015) identificaram que a maioria das pesquisas enfatiza algum tipo específico de deficiência e poucas consideram grupos mistos de crianças. E, por ser justamente na coletividade que a criança com deficiência tem a possibilidade do desenvolvimento completo de suas funções psicológicas superiores, conforme esclarece Vigotski (1997), é que se recomenda a realização de atividades em grupos mistos - diferentes deficiências e crianças típicas.

A carência de pesquisas, notadamente no Brasil, acerca da aprendizagem por meio de desenvolvimento de jogos digitais, motivou a pesquisa ora apresentada, que contou com o envolvimento dos participantes - alunos do ensino fundamental e do ensino superior - e visou contribuir para a área da educação que se recente de processos metodológicos articuladores de tecnologia, aprendizagem e criatividade.

Neste contexto, elaborou-se a pesquisa em nível de doutorado em Educação cujo objetivo geral foi construir um processo metodológico mediado e colaborativo que faculte a atuação criadora de crianças com e sem deficiências no desenvolvimento de jogos digitais. Mais especificamente buscou-se: a) examinar as atividades, comportamentos e interação das crianças em experiências com jogos digitais e analógicos; b) avaliar as atividades de transposição de jogos digitais para analógicos e vice-versa; c) analisar a relação entre crianças, pesquisador e 
acadêmicos na mediação do processo de desenvolvimento de jogos digitais; d) identificar os avanços e dificuldades, processos e documentação com vistas a validação da metodologia proposta (Alves, 2017).

Adotando os pressupostos da abordagem histórico-cultural de Vigotski estreitamente relacionados a aprendizagem de alunos com deficiência intelectual e sua inclusão escolar: a coletividade, a colaboração, a experiência e a mediação simbólica, definiu-se o framework "Eu fiz meu game" que visa a criação de jogos digitais por e com crianças. Este artigo é uma extensão do trabalho publicado nos Anais dos Workshops do VI Congresso Brasileiro de Informática na Educação (Alves, Hostins, e Raabe, 2017). Apresenta-se a abordagem metodológica da pesquisa, detalhada na seção 2, as bases conceituais da pesquisa na seção 3, os resultados evidenciados pela definição do framework e das principais atividades desenvolvidas com os alunos, detalhados na seção 4, e por fim as considerações finais, seção 5, em que se discutem os principais resultados.

\section{Metodologia}

Adotou-se na pesquisa a abordagem qualitativa, baseada no Design-based Research (DBR), o qual alia a pesquisa em educação aos problemas e questões vivenciados na prática, de forma a produzir conhecimento utilizável. A abordagem considera uma profunda colaboração entre pesquisadores e participantes no sentido de alcançar os objetivos teóricos e práticos da pesquisa, resultando em dilatadas mudanças educacionais práticas (Wang e Haffanin, 2005). Para Baumgartner et al (2003) a abordagem pode “[...] ajudar a criar e ampliar o conhecimento sobre o desenvolvimento, adoção e manutenção de ambientes de aprendizagem inovadores”. O DBR é compreendido como um processo que propicia interações e conduz ao desenvolvimento de teorias. Divide-se em quatro fases, conforme descreve-se no Quadro 1:

Quadro 1 - Fases do Design-based Research

\begin{tabular}{|c|c|c|}
\hline \multicolumn{2}{|r|}{ Fase } & Descrição \\
\hline Fase 1 & $\begin{array}{l}\text { Análise de um problema prático } \\
\text { pelos pesquisadores e participantes } \\
\text { em colaboração }\end{array}$ & $\begin{array}{c}\text { Deve levantar o problema junto aos participantes. Mas este } \\
\text { também pode vir do orientador e suas linhas de pesquisa. } \\
\text { Revisão da literatura para apoiar o “rascunho” da intervenção. } \\
\text { Esta deve ser contínua no processo. }\end{array}$ \\
\hline Fase 2 & $\begin{array}{l}\text { Desenvolvimento de soluções } \\
\text { informadas pelos princípios de } \\
\text { design existentes e inovações } \\
\text { tecnológicas }\end{array}$ & $\begin{array}{l}\text { Aqui é definida a descrição da intervenção proposta, } \\
\text { baseando-se num arcabouço teórico. São definidos o rascunho } \\
\text { e princípios da intervenção. }\end{array}$ \\
\hline Fase 3 & $\begin{array}{l}\text { Ciclos iterativos de teste e } \\
\text { refinamento das soluções na prática }\end{array}$ & $\begin{array}{l}\text { Implementação da intervenção em iterações. Estas devem ser } \\
\text { em dois ou mais ciclos. Definição dos participantes. Coleta e } \\
\text { análise dos dados. As próximas intervenções são definidas } \\
\text { após a anterior, pois dependem dessas (resultados). }\end{array}$ \\
\hline Fase 4 & $\begin{array}{l}\text { Reflexões para produzir “princípios } \\
\text { de design” e melhoria da solução } \\
\text { implementada }\end{array}$ & $\begin{array}{l}\text { Apresentar os conhecimentos e produtos. Princípios e } \\
\text { artefatos do design. }\end{array}$ \\
\hline
\end{tabular}

A abordagem considera a complexa interação entre as intervenções tecnológicas, os papéis das instituições educacionais e os propósitos da educação. Neste sentido Amiel e Reeves (2008) apontam para uma visão ampliada do uso das tecnologias educacionais, compreendendo-as como um processo, em vez de um produto, destacando o DBR como uma alternativa à forma preditiva de pesquisa, notadamente quando se envolve tecnologia.

O DBR foi adotado na especificação do framework "Eu fiz meu game”, fundamentado na prática pela sua instanciação junto a alunos do ensino fundamental. O grupo, composto por quatro 
crianças de nove anos de idade, cursando o terceiro/quarto ano, desenvolveu atividades de criação de jogos digitais em parceria com pesquisadores das áreas de Educação, Computação e Design de Jogos. Fizeram parte do grupo uma menina com deficiência intelectual e um menino com autismo associado a deficiência intelectual. Também constituiu o grupo, um acadêmico de Engenharia de Computação. O projeto foi aprovado pelo comitê de ética sob o $\mathrm{N}^{0}$ 23083.007306/2012-61, autorizado pela Secretaria de Educação do Município de Itajaí - SC - Brasil, bem como pelos responsáveis das crianças por meio do Termo de Consentimento Livre e Esclarecido (TCLE), incluindo uso de imagens. Realizaram-se 25 sessões semanais de uma ou duas horas-aula em uma escola da rede municipal de ensino, nos anos de 2015 (23 sessões) e 2016 (duas sessões). Foram coletados dados por meio de fotografias, vídeos, fichas de avaliação, artefatos construídos pelas crianças, artefatos de software, dentre outros.

Para análise dos dados efetuou-se a análise narrativa que tem como base a ideia de reconstruir acontecimentos sociais a partir do ponto de vista dos sujeitos envolvidos. Essa abordagem foi significativa para recompor o processo de construção do framework. A narrativa como um método opõe-se ao modelo lógico-científico, e implica uma abordagem subjetiva e interpretativa que considera os indivíduos em seus ambientes sociais, interagindo e atribuindo significado aos objetos do mundo (Bamberg, 2012).

\section{Referencial teórico}

A definição do framework "Eu fiz meu game" alicerçou-se em dois pilares: o design de jogos com crianças e os conceitos de aprendizagem e cognição. Esses foram necessários para a compreensão dos aspectos acerca de como se desenvolve jogos digitais na perspectiva da educação e dos fundamentos sobre aprendizagem e desenvolvimento da criatividade na infância. As subseções a seguir abordam os fundamentos da pesquisa.

\subsection{Design de jogos com crianças}

Uma área de estudos emergente é a Interação Criança-computador (ICC), que busca investigar as especificidades da interação das crianças com as tecnologias, enfocando a ludicidade e as oportunidades de aprendizagem, em especial nos espaços escolares, onde as crianças passam a maior parte do tempo (Read e Markopoulos, 2013; Modesto e Mustaro, 2014). A ICC deriva-se dos estudos referentes a área de IHC - Interface Humano Computador - a qual investiga a adequação das interfaces para os seres humanos, e foi inicialmente voltada aos sistemas computacionais, visando produtividade, comunicação e controle.

Uma abordagem de projeto para IHC, e consequentemente ICC, é o Design Participativo, o qual busca, por meio da participação dos usuários finais, aproximar-se das suas necessidades, desejos e formas de pensar. Muller e Druin definem que "Design Participativo (PD) é um conjunto de teorias, práticas e estudos relacionados à participação plena dos usuários finais em atividades que levam aos produtos de software e hardware e às atividades baseadas em computador.” (2010, pp. 3, tradução nossa). Mas o DP vai além do design, envolvendo os usuários na fase de produção, quando possível, mas em especial nas fases de avaliação do software.

Estudos recentes em ICC focam em metodologias que buscam a melhor forma de avaliar e produzir produtos com e por crianças, envolvendo-as como participantes ativas no processo de design (Read e Markopoulos, 2013). É neste contexto que Moser (2015) define o Child-centered game development (CCGD) que propõe e avalia um framework metodológico para o design e desenvolvimento de jogos por e com pré-adolescentes no contexto escolar. O CCGD apresenta a seguinte abordagem: 
1. tem objetivos claros que as crianças podem compreender e oferece a possibilidade de aplicar os conhecimentos existentes;

2. estimula e motiva as crianças a fim de obter algo além de participar (ou seja, apoiar uma situação win-win ${ }^{1}$ e honrar as vozes das crianças);

3. apoia a diversidade das crianças e oferece uma grande variedade de envolvimento das crianças, a fim de abordar as diferentes preferências de expressarem-se;

4. adapta aos diferentes níveis de leitura e escrita, sendo bom para pré-adolescentes (crianças com idade entre 10 a 13 anos) e;

5. assegura a recolha dos dados necessários para pesquisadores da área de jogos, designers ou desenvolvedores (por exemplo, com dados de diversificadas fontes para uma melhor qualidade). (Moser, 2015, pp. 18-19, tradução nossa)

O CCGD é composto por cinco fases: análise, conceito, design, implementação e avaliação, abrangendo dessa forma todas as etapas de criação de um jogo digital, tal como proposto em processos da indústria de jogos, como em Novak (2011). O que diferencia o framework são as abordagens de design que incluem a criança em todas as atividades, por meio de técnicas como ciclo de ideias, cartões de perguntas, brainstorm, jogo das personas, implementação por meio do Scratch ou Kodu, dentre outras. Nesse sentido, o DP se destaca por propiciar o envolvimento das crianças, fundamental para proporcionar seu protagonismo.

A estratégia pedagógica proposta no CCGD é o design centrado no aluno, que visa compreender suas necessidades, compreender como aprende, ter motivação como base da aprendizagem, considerar a diversidade e ter o crescimento como desafio. Os princípios para esta abordagem consideram a criação de um relacionamento interpessoal positivo, o respeito e consideração à fala das crianças e o incentivo ao pensamento de ordem superior e a autorregulação (Moser, 2015). Esses princípios defendidos pela CCGD são particularmente interessantes e se conectam com a pesquisa apresentada neste artigo, especialmente por sua preocupação com o protagonismo das crianças, a interação e o desenvolvimento do pensamento.

Outro trabalho relevante que embasou a pesquisa encontra-se em Li (2014), que destaca a diferenciação entre o game design, cujo foco é o produto, e a aprendizagem pelo game design, cujo foco é a aprendizagem. A abordagem epistemológica adotada por Li rejeita o dualismo que separa mente do corpo, indivíduo do ambiente ou sujeito do objeto. Li defende que:

Aprendizagem e cognição, ao contrário do que geralmente se pensa, podem começar sem
a ação consciente do estudante ou objetivos prescritos. Na verdade, quase o oposto ocorre
quando os estudantes aprendem e sabem através de uma imersão deles mesmos num
mundo complexo onde eles podem jogar, experimentar e interagir uns com os outros e
com o ambiente. (Li, 2014, pp. 9, tradução nossa)

Os fundamentos para a aprendizagem por meio de jogos digitais, proposta na abordagem de Li, baseiam-se em Lev Vigotski, Seymour Papert e James Paul Gee, destacando: o conceito de Zona de Desenvolvimento Proximal (ZDP) em Vigotski, o construcionismo ${ }^{2}$ em Papert e os conceitos de aprendizagem por meio de vídeo games em Gee (Li, 2014, pp. 19-22).

Para a aprendizagem por meio de design de jogos, Li propõe um modelo nominado Learner Design Education Game (LDEG) ${ }^{3}$ que provê um framework detalhado para guiar estudantes no design e construção de jogos educativos. A abordagem educacional proposta por Li é pedir aos estudantes que criem jogos educacionais com o objetivo de ensinar outras pessoas acerca de algum

\footnotetext{
${ }^{1}$ Win-win é uma expressão que se refere a situações em que ambos os lados de um negócio, ou atividade, saem ganhando. Neste caso, refere-se aos designers e às crianças (nota da autora).

${ }^{2}$ Papert definiu o termo Construcionismo que estabelece que a aprendizagem ocorre quando os estudantes ativamente reconstroem seus conhecimentos, em vez de apenas serem transmitidos pelos outros. O autor explorou o uso de computadores nesta abordagem.

${ }^{3}$ Design de jogos educacionais por estudantes (tradução nossa).
} 
conhecimento. Por meio da criação do jogo, os próprios estudantes irão construir seus conhecimentos sobre o tema abordado (Li, 2014, pp. 81-82). Para a autora, esta abordagem permite o desenvolvimento da criatividade e inovação, do pensamento crítico e resolução de problemas e da comunicação e colaboração - habilidades necessárias para o Século 21. Reconhece-se o LDEG como uma abordagem positiva para a aprendizagem por meio de criação de jogos digitais, e essa trouxe excelentes contribuições para a pesquisa, contudo, o framework "Eu fiz meu game” diferencia-se por não estabelecer temáticas para o jogo a ser desenvolvido, procurando focar o desenvolvimento da criatividade mais que a aprendizagem de conteúdos escolares específicos.

Apesar da semelhança dos trabalhos de Moser e Li com a presente pesquisa, não foram encontradas nesses evidências de pesquisas referentes a inclusão escolar de crianças com deficiência intelectual, objeto deste estudo. Desta forma, buscou-se identificar na literatura de que forma o design de jogos vem sendo adotado como estratégia para aprendizagem de estudantes com deficiência.

A participação de crianças com deficiência no processo de criação de tecnologias foi investigada por Börjesson, Barendregt, Eriksson, e Torgersson (2015) que constataram que há um crescente aumento de pesquisas que incluem crianças com deficiências em processos de design, porém ainda com pouco envolvimento ativo dessas. O estudo, que avaliou 88 trabalhos na área, revelou que somente 17 incluíram as crianças em todo o processo de projeto - definição de requisitos, design e avaliação - enquanto os demais detiveram-se a uma ou duas fases do processo. Evidenciou-se também que a maioria das pesquisas se dirigem a um determinado tipo de deficiência, destacando que 50\% são voltadas para crianças com autismo de alta funcionalidade, como no estudo de Benton et al (2012). Os autores identificaram somente 2,2 \% de trabalhos com foco em pessoas com deficiência intelectual e 13\% de grupos mistos, isto é, crianças com diferentes deficiências atuando em conjunto, como no estudo de Foss et al (2013).

A pesquisa colaborativa, um subconjunto do DP, foi a abordagem adotada por Foss et al (2013) para o desenvolvimento de jogos com um grupo de 10 meninos entre 11 e 12 anos em uma sala de aula com diferentes necessidades especiais de aprendizagem, incluindo crianças com autismo leve a moderado, dislexia e déficits de atenção. Os estudantes frequentavam uma escola privada especializada em educação especial. Os autores destacam a adaptação de métodos de design conforme as necessidades dos alunos, e revisam boas práticas dentre elas a adoção de grupos pequenos de alunos, a inclusão de mais adultos na equipe (dependendo do caso um por aluno) e a flexibilização dos métodos. Dentre as técnicas da pesquisa colaborativa foram adotadas Big Paper, Mixing Ideas, Storyboarding, Bags of Stuff, Stickie, KidReporter. Por meio de oito sessões, os pesquisadores desenvolveram um jogo em parceria com as crianças e desenvolvedores. A pesquisa revela que as crianças como parceiras do design sentiram-se protagonistas de suas ideias e que houve um alto nível de envolvimento emocional. Os autores recomendam (i) incluir um tempo em cada sessão para a socialização e conversas informais, no intuito de estreitar os laços entre os membros do grupo; (ii) uma proporção maior de adultos por crianças, pois foi muito difícil atender todos por meio de rodízio dos pesquisadores entre os pequenos grupos; (iii) informar instruções por escrito além de oralmente, pois algumas crianças tem dificuldades auditivas; (iv) maior envolvimento das crianças nas etapas de desenvolvimento do jogo, a qual foi realizada apenas pelos designers adultos.

Apesar de Foss et al incluírem diferentes deficiências em sua pesquisa, os autores não incluem crianças sem deficiência no processo, cabendo somente aos adultos a mediação com as crianças nos seus processos de aprendizagem. O foco a um tipo de deficiência, ou apenas crianças com deficiências, é destacado por Börjesson, Barendregt, Eriksson, e Torgersson (2015) como problemático, pois a aplicação de uma tecnologia no mundo real, como em uma escola, encontrará 
uma diversidade de crianças a utilizá-la. Dessa forma, os autores apontam como uma recomendação "Conceber e investigar abordagens e métodos destinados a grupos mistos de crianças, tanto as crianças com diferentes deficiências, bem como deficiências intelectuais e cognitivas diversas e crianças com desenvolvimento típico.” (pp. 85, tradução nossa). Nessa perspectiva, tomando por base os trabalhos avaliados, os autores elaboraram uma síntese de diretrizes e recomendações para o envolvimento de crianças de diferentes deficiências no processo de design. Dentre elas, destacam-se:

[...] permitir que pessoas que conheçam bem a criança realizem o primeiro contato, abordar a criança gradualmente e observar como essas pessoas interagem com a criança. [...] ser flexível no uso de métodos e estar preparado para adaptar.

[...] interagir com quantos cuidadores quanto possível.

[...] envolver pesquisadores com diferentes formações, pois isto é importante para ter uma equipe de adultos com habilidades tanto técnicas quanto de conhecimentos psicológicos para um melhor envolvimento das crianças.

[...] envolver a criança em atividades prazerosas de design, como jogos, desenhos e contação de histórias.

[...] usar interações de baixa tecnologia para projetar aplicações de alta tecnologia.

[...] usar os pontos fortes pessoais de cada criança para construir sua confiança nas sessões. (Börjesson et al., 2015, p. 84-85, tradução nossa).

O estudo de Börjesson et. al. trouxe contribuições significativas para a pesquisa, pois sintetiza diversos aspectos do desenvolvimento de tecnologias com e por crianças com deficiência, com destaque à síntese organizada acerca dos métodos e técnicas adotados nos estudos avaliados, ao papel da criança no processo de criação e diretrizes para um envolvimento eficiente. A escassez de pesquisas envolvendo crianças em grupos mistos em todo o processo de criação de uma tecnologia, evidencia a relevância da investigação ora apresentada.

\subsection{Aprendizagem e cognição}

A abordagem educativa e pedagógica da pesquisa apoiou-se nas teorias sobre criatividade e imaginação na infância descritas por Vigostki, porque “[...] a imaginação é condição absolutamente necessária de quase toda atividade intelectual do homem.” (Vigotski, 2014, p. 15). O autor compreende por atividade criativa aquela que produz algo novo, mesmo que possa parecer ínfimo. Dessa forma, Vigostki esclarece que não são apenas as grandes obras artísticas ou científicas que devem ser consideradas como expressão da criatividade, mas tudo aquilo em que existe a imaginação, combinação, alteração e criação do novo.

Compreender o mecanismo da imaginação criativa permite elaborar caminhos que levem ao desenvolvimento da criatividade e consequentemente ao desenvolvimento intelectual da criança. Vigostki descreve esse mecanismo, o qual divide-se em três principais processos: percepção, elaboração e cristalização (Vigotski, 2014, pp. 25-33):

a) A percepção é o fundamento das experiências, adquiridas pelos nossos sentidos e que permitem o acúmulo de materiais necessários aos processos imaginativos;

b) A elaboração divide-se em dois processos, sendo o primeiro o de dissociação em que o sujeito fragmenta os materiais, divide em partes menores, compara, seleciona e modifica. Esse processo é fundamental para o desenvolvimento do pensamento abstrato e elaboração de conceitos. No segundo processo nominado associação, há a junção dos elementos dissociados e modificados, podendo adotar formas e bases diferentes dos materiais originais percebidos no início do processo;

c) A cristalização é a conversão da imaginação em imagens exteriores, completando e efetivando a atividade criativa. Essas imagens exteriores são o resultado do processo criativo: um produto, um conceito, um texto, um desenho. 
Compreende-se, conforme Vigotski adverte, que "[...] a lei básica da criatividade infantil consiste em que o seu valor não reside no resultado, no produto da criação, mas no próprio processo" (Vigotski, 2014, p. 90). Dessa forma, ao adotar-se o desenvolvimento de jogos digitais por e com as crianças, necessita-se engendrar o processo de tal forma que esse associe-se ao processo criativo descrito por Vigotski e favoreça o desenvolvimento da criatividade das crianças, independente dos produtos - jogos - que venham a ser desenvolvidos.

Para apoiar o processo da imaginação criativa, toma-se o conceito de mediação simbólica, o qual permite ao sujeito ampliar sua compreensão por meio da utilização de signos como estímulo auxiliar para a complementação da operação mental por meios indiretos. No processo mediado, o estímulo auxiliar confere à operação psicológica formas qualitativamente novas e superiores, outorgando ao ser humano a capacidade de controlar seu próprio comportamento (Oliveira, 1995). O papel da intervenção pedagógica, neste caso, se dá por meio da mediação no sentido de questionar, provocar, dar pistas, orientar e desafiar constantemente as crianças em seus processos criativos. Isto se alinha às relações entre desenvolvimento e aprendizado, sobretudo à concepção de zona de desenvolvimento proximal (ZDP).

Ela [a zona de desenvolvimento proximal] é a distância entre o nível de desenvolvimento real, que se costuma determinar através da solução independente de problemas, e o nível de desenvolvimento potencial, determinado através da solução de problemas sob a orientação de um adulto ou em colaboração com companheiros mais capazes. (Vigotski, 2007, p. 97)

É justamente na ZDP que a “interferência com outros indivíduos é mais transformadora”, como nos salienta Oliveira (1995, p. 61). Portanto, a partir daquilo que a criança já sabe, pode-se interferir por meio de intervenções que promovam avanços no aprendizado do aluno, algo que ele não conseguiria sozinho. O educador, ou mesmo um colega com mais conhecimento, enquanto mediador do aprendizado, faz o elo para o desencadeamento de habilidades que a criança já tem condições de desenvolver. Esta é uma condição fundamental para o desenvolvimento intelectual de cada criança.

Para Vigotski o desenvolvimento intelectual passa necessariamente pela vivência do indivíduo no meio em que está inserido. Tanto a criança quanto o meio se modificam ao longo da existência, e novos significados são construídos nesse processo. Para esta construção, é necessário que a criança tenha em suas relações sociais formas ideais ou superiores de desenvolvimento que a influenciem no sentido de se desenvolver a partir de suas formas primárias ou iniciais. Quando por qualquer motivo se rompe a relação entre a forma ideal e a inicial, o desenvolvimento se torna limitado e a consequência é o subdesenvolvimento desta ou daquela propriedade intelectual.

No meio existem essas formas ideais desenvolvidas, elaboradas pela humanidade, aquelas que deverão surgir ao final do desenvolvimento. Essas formas ideais influenciam a criança desde os primeiros passos que ela dá rumo à dominação da forma primária. E, no decorrer de seu desenvolvimento, a criança se apropria, transforma em suas aquisições interiores aquilo que, a princípio, era sua forma de interação externa com o meio. (Vigotski, 2010, p. 698)

Compreende-se desta forma a importância de oferecer às crianças, especialmente para as crianças com deficiência intelectual, um meio em que as formas ideais do conhecimento e cultura estejam disponíveis para o desenvolvimento das suas funções superiores. Assim, as vivências com adultos ou crianças intelectualmente mais desenvolvidas, por meio de ações coletivas e colaborativas, auxiliarão aquelas com maior dificuldade. Para Vigotski, o desenvolvimento incompleto das funções superiores da criança com deficiência é uma superestrutura secundária ao defeito:

O desenvolvimento incompleto decorre do fato que podemos chamar <<exílio >> da criança anormal da comunidade. Aqui, o processo ocorre da seguinte maneira: à raiz de 
um determinado defeito, aparece na criança uma série de características que dificultam o desenvolvimento normal da comunicação coletiva, da colaboração e da interação dessa criança com as pessoas que o rodeiam. $\mathrm{O}$ afastamento da coletividade ou a dificuldade de desenvolvimento social, por sua vez, determina o desenvolvimento incompleto das funções psíquicas superiores, as quais, quando é normal o curso das coisas, surgem diretamente em relação com o desenvolvimento da atividade coletiva da criança (Vigotski, 1997, pp. 223, tradução nossa)

Ao se analisar os pressupostos de Vigotski com relação a aprendizagem de crianças com deficiência intelectual, Silva, Hostins, e Mendes (2016) concluem que a mediação e interação para resolução de problemas são fundamentais para os processos cognitivos dos indivíduos. Isto requer que professores de salas regulares e do Atendimento Educacional Especializado (AEE) dominem tanto os conhecimentos do campo da didática, quanto aqueles das mais diversas áreas do conhecimento, os quais precisam ser mobilizados por meios apropriados (instrumentos e signos). Para as autoras "A compreensão desses pressupostos pelo professor, no ambiente escolar, culminaria no exercício de uma 'pedagogia do coletivo' centro da abordagem histórico-cultural.” (Silva, Hostins, e Mendes, 2016, p. 26)

Ao se compreender os mecanismos da criatividade - e sua relevância para o desenvolvimento intelectual - e a importância da mediação e interação para os processos cognitivos, o framework proposto nesta pesquisa evidencia os processos de colaboração, coletividade, experiência e mediação favorecidos pelas atividades de criação de jogos digitais.

\section{Resultados}

Por meio da metodologia do Design Based-research, o framework "Eu fiz Meu Game" foi definido no decorrer do processo de investigação com os participantes da pesquisa. A cada sessão com as crianças, reviam-se os pressupostos e estabeleciam-se os objetivos e as atividades para as próximas sessões. Nesta construção gradativa e incremental, teoria e prática se alinharam de forma a permitir o estabelecimento de um arcabouço consistente para um processo de construção de jogos digitais com crianças.

A pesquisa partiu da compreensão de que a participação das crianças, notadamente as com deficiência intelectual, na construção dos jogos, e não somente no jogar, pode permitir o desenvolvimento da imaginação e criatividade na infância e consequentemente das funções psicológicas superiores, como habilidades de concentração, atenção, raciocínio, memória (auditiva, seletiva, sonora, visual), necessárias ao pensamento complexo, aliando os conceitos do design participativo às concepções de aprendizagem e desenvolvimento do campo da psicologia histórico-cultural desenvolvida por Vigotski.

Do ponto de vista do design de jogos digitais, adotou-se como principal referencial de processos de jogos a abordagem proposta por Novak (2011) que estabelece um processo composto por oito fases: conceito, pré-produção, protótipo, produção, alfa, beta, ouro e pós-produção. Nestas, abordam-se as atividades necessárias para a concepção de um jogo digital desde as ideias iniciais até sua entrega aos clientes, incluindo as técnicas de design e construção necessárias à finalização do jogo.

As contribuições de Moser (2015) e Li (2014) envolvendo crianças em processos de desenvolvimento de jogos digitais, foram avaliadas de forma a serem observados os processos adotados, as técnicas e os resultados obtidos. Destacam-se inúmeras técnicas de design e estratégias que de forma semelhante foram adotadas nesta pesquisa, entretanto não foram evidenciadas a participação de crianças com deficiencias nesses trabalhos, o que the confere um diferencial em relação a essas abordagens. 


\subsection{O framework "Eu fiz meu game"}

“Eu fiz meu game” é um framework de desenvolvimento de jogos digitais com e por crianças no contexto escolar (Alves, 2017). O framework requer a participação ativa dos envolvidos educadores, acadêmicos e crianças - por meio de atividades que englobam todas as etapas pedagógicas e de design para o desenvolvimento de um jogo digital. Para tanto, o processo é composto por quatro etapas, conforme apresenta a Figura 1, a saber: (i) Envolvimento, (ii) Experiência, (iii) Transposição e (iv) Criação de Jogos Digitais. Destaca-se como ação transversal a mediação simbólica, compreendida como condição necessária à cada etapa ou atividade a ser realizada e a fundamentação para o desenvolvimento cognitivo proposto nos subprocessos.

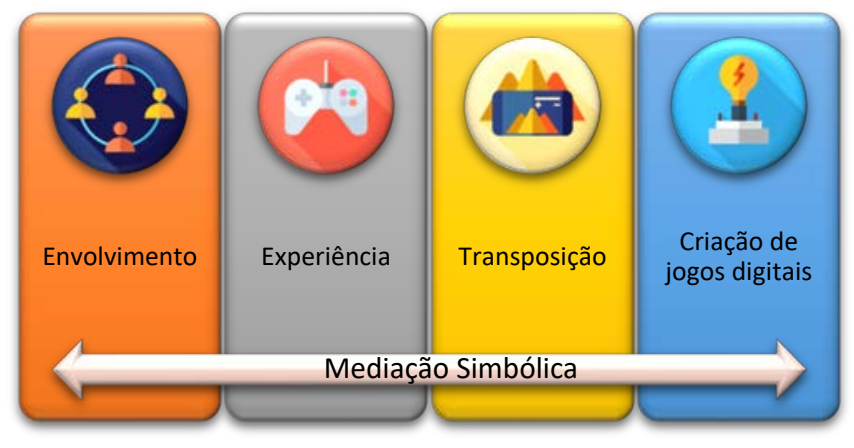

Figura 1: Framework "Eu fiz meu game".

Fonte: Alves (2017)

\subsubsection{Etapa de envolvimento}

A etapa de Envolvimento consiste no engajamento dos participantes no projeto e sua integração. Constitui-se etapa essencial para o estabelecimento de um relacionamento de confiança entre educadores e crianças, facultando seguir para as etapas posteriores. Além disso, possibilita aos educadores identificar algumas características das crianças em termos de aprendizagem e relacionamento, apontando diretrizes para o planejamento das atividades. Esses aspectos são particularmente relevantes quando o grupo envolve crianças com algum tipo de deficiência.

No contexto da prática, a Etapa de Envolvimento teve uma duração de três sessões. Realizouse uma reunião motivacional em que se convidaram as crianças a participar do projeto. Nesta ocasião perguntou-se: como vocês acham que os jogos digitais são criados? A resposta de uma das meninas merece destaque: “abaixando" (download). Essa alternativa de resposta demonstra 0 que Vigostski chama de conceito preliminar, o qual se constrói pautado na experiência imediata e prática das crianças com o objeto de conhecimento. Este irá se transformar no transcorrer do projeto.

As próximas atividades consistiram em construir objetos com sucatas e a partir desses elaborar uma história. Cada criança recebeu um "kit” - pedaços de EVA, bobs para cabelo, grampo de roupa, canudinho - e solicitou-se que criassem "qualquer coisa” a partir desses objetos. A atividade individual adquire sentido no grupo e a coletividade cria novos significados. As crianças iniciam a jornada do trabalho colaborativo, e a mediação por meio dos objetos, diálogos e criações possibilitam as primeiras criações do grupo. A Figura 2(a) apresenta as crianças na atividade de criação de objetos e a Figura 2(b) um dos cenários desenhado para a história. 


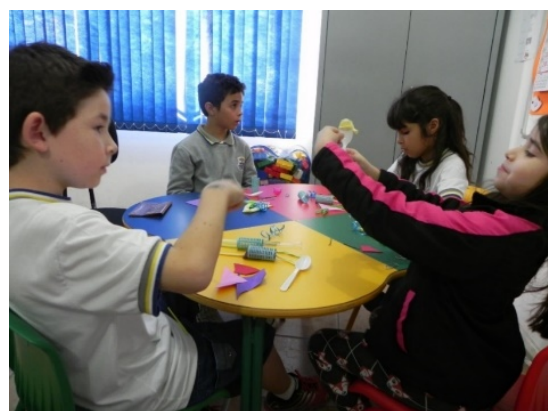

(a) Crianças criando objetos com sucata

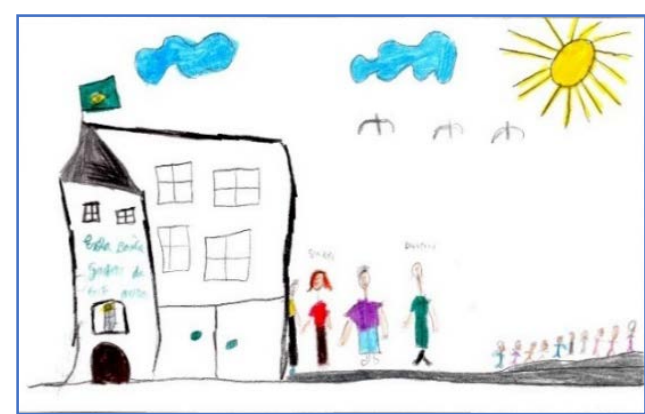

(b) Cenário da história criada pelo grupo

Figura 2: Atividades da etapa de Envolvimento.

Fonte: Alves (2017)

No desenvolvimento das atividades, evidenciou-se a mediação entre pesquisadora-aluno e aluno-aluno. Pesquisadoras intervinham com perguntas e solicitações para que as crianças ajudassem um dos colegas, que apresentava dificuldades em construir um objeto de sucata. As crianças observavam as criações dos colegas e inspiravam-se nelas para construir seus próprios objetos.

A construção de objetos a partir de elementos aparentemente sem relação entre si tornou-se um desafio às crianças, que buscaram conceitos de seu repertório - um boneco, uma espada, um vai-e-volta - para dar significado às suas criações. Evidenciam-se aqui os primeiros movimentos em direção ao desenvolvimento da criatividade, por meio da dissociação dos objetos, sua separação, análise e comparação, para depois criar associações, como transformar uma colher de plástico e um pedaço de EVA em um boneco, convertendo a imaginação nessas "imagens exteriores”, como afirma Vigotski.

Foi importante observar os comportamentos das crianças nesta etapa, suas características e fragilidades. Como por exemplo, a dificuldade de uma das meninas em nomear o objeto criado, e sua estratégia em obter sugestões dos colegas, como se observa no trecho do diálogo abaixo:

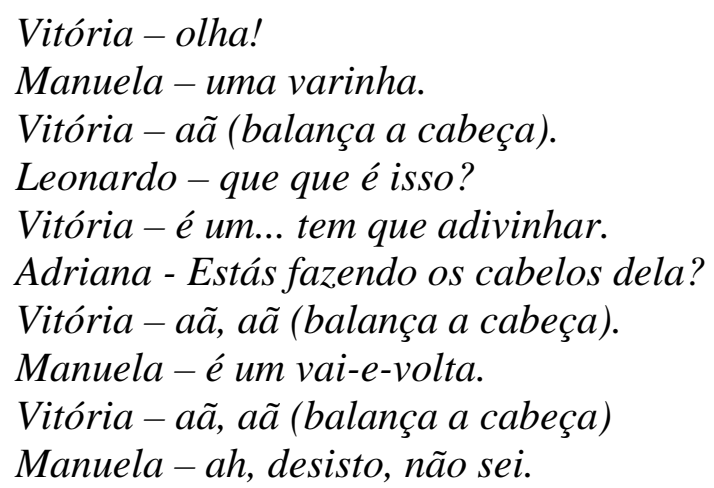

Estudos revelam que as crianças aprendem mais quando trabalham em grupos que individualmente, no entanto, é necessária a busca por um objetivo comum para trazer significado e motivação para as atividades colaborativas (Moll, 1996, p. 164). Dessa forma, propôs-se a criação de uma história a partir dos objetos criados pelas crianças. Evidenciamos nessa experiência o trabalho colaborativo na construção de algo novo em conjunto. Revelaram-se conflitos: "professora, essa ideia acho que não é muito boa não" diz Leonardo, ao que replica Vitória "eu acho boa”; solidariedade: “assim ó, eu vou ajudar ela, a ideia da Vitória...” diz Manuela; colaboração: "aqui, faz a gravata aqui” diz Leonardo pegando na mão de Raphael para ajudá-lo a desenhar. Apesar da necessidade de contínuas negociações de sentidos e consensos e de algumas dificuldades enfrentadas, o grupo foi capaz de finalizar a história, contando constantemente com a mediação das pesquisadoras. Vigotski (2014, p. 45) afirma que "criar é 
difícil” e nem sempre os impulsos para criar coincidem com a capacidade do sujeito para a tarefa, o que gera um sentimento de tortura e sofrimento, ao que denominou “Os tormentos da criação”. Estes sentimentos constituem a característica mais importante da criação, pois que significam o desejo da imaginação para a criação. "Qualquer construção da imaginação, partindo da realidade, tende a descrever um ciclo completo e a encarnar de novo a realidade” (Vigotski, 2014, p. 47).

\subsubsection{Etapa de experiência}

A etapa de Experiência visa ampliar o conhecimento das crianças acerca de jogos analógicos e digitais. A riqueza e variedade das experiências permitem o acúmulo de materiais necessários à imaginação (Vigotski, 2014), dessa forma necessita-se ampliar essa experiência caso deseja-se o desenvolvimento da atividade criativa das crianças. Considera-se que para a criação de novos jogos são indispensáveis a experiência com jogos e a reflexão dos elementos que os compõem.

As atividades propostas nessa etapa, que tiveram a duração de três sessões, são momentos de lazer e reflexão com jogos analógicos (tabuleiros, cartas) ou digitais (computadores, tablets, smartphones). Desta forma realizaram-se atividades lúdicas com o jogo Base 3 (analógico) seguido de sua versão digital, o jogo Dinobase, como apresenta a Figura 3. Esses trabalham conceitos matemáticos de potenciação, especificamente da base 3 (Alves, Cathcart, e Hostins, 2014). Posteriormente trabalharam-se jogos que não tinham relação entre si: o jogo analógico "Hora do rush" que visa a resolução de problemas por meio de raciocínio lógico (BigStar Brinquedos, 2016) e o jogo digital de estratégias "Where's my water" (Disney Entertainment, 2016).

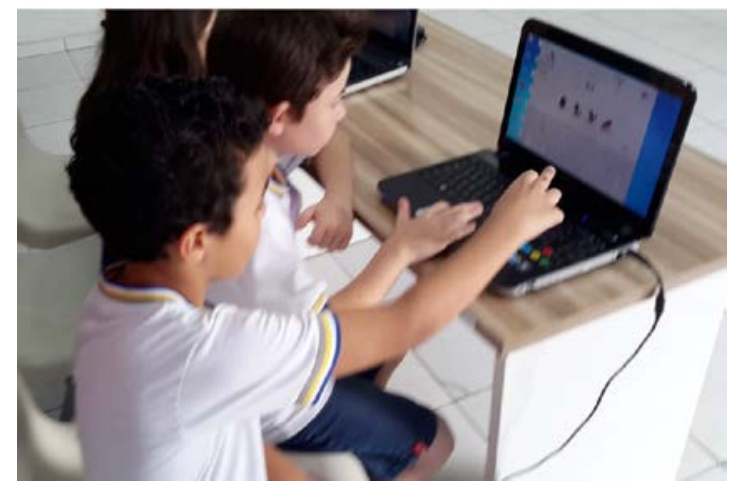

Figura 3: Raphael e Leonardo jogando Dinobase.

Fonte: Alves (2017)

É notório que as crianças já conheciam jogos, porém nas atividades propostas instigou-se para que refletissem sobre os componentes do jogo - regras, metas ou objetivos, resultados e feedback, conflito, interação, representação ou enredo - (Prensky, 2012, p. 172) e desta forma construíssem conceitos necessários ao futuro desenvolvimento de um jogo digital. Isso se evidenciou particularmente na percepção das crianças com relação às mecânicas dos jogos Base 3 e Dinobase. Ao serem questionadas sobre os dois jogos, uma das meninas respondeu "porque os dois são o mesmo igual jogo" e a outra "o mesmo significado". Os signos utilizados - figuras geométricas e dinossauros - apesar de diferentes, representam a mesma coisa, têm o mesmo "significado", nas palavras da criança. Por meio dessa atividade mediada percebeu-se a formação do conceito do que é um jogo.

\subsubsection{Etapa de transposição}

A etapa de Transposição propõe promover a percepção da criança acerca do processo de criação de um jogo digital. Diferente da etapa de Experiência, em que a criança utilizou jogos prontos, 
nesta ela vai criar seus próprios jogos em meio digital. Aqui propõe-se a elaboração de jogos utilizando ferramentas de autoria em jogos que sejam simples e acessíveis ao nível de conhecimento das crianças.

Selecionou-se como ferramenta de autoria o app Inventame que permite a implementação de jogos a partir da interação entre o mundo real e o mundo virtual. $\mathrm{O}$ app não exige nenhuma habilidade de programação para a criação do jogo, o usuário interage por meio de objetos e desenhos reais ou virtuais para criar o cenário, em seguida define as regras e o comportamento do seu jogo (Ibáñez, 2015). Este tipo de recurso favorece a participação das crianças, em especial aquelas com deficiência, que podem ainda não terem desenvolvido as habilidades de escrita e leitura, como era o caso dos alunos envolvidos na pesquisa. Ou seja, mesmo sem saberem escrever, em especial linhas de código, elas foram capazes de criar jogos digitais.

As criações de jogos com o Inventame foram realizadas de forma individual e coletiva, e tiveram a duração de quatro sessões. As atividades permitiram que pela primeira vez as crianças construíssem seus próprios jogos, ainda que restritas às possibilidades do app. A atividade colaborativa foi mediada pelas pesquisadoras, que incentivaram o trabalho de todos, questionaram, conduziram as crianças à reflexão. A interação entre as crianças também trouxe elementos importantes para o trabalho coletivo, pois elas discutiram as ideias, criaram hipóteses, encontraram soluções para os problemas encontrados. Para De Paula, Valente e Hildebrand (2016, p. 14), a colaboração na criação de jogos digitais por crianças evidencia o sucesso desse tipo de iniciativa. A intenção foi oportunizar um processo de atividade intelectual favorecido pela colaboração coletiva que, segundo Vigotski (1997) precedem as formas individuais de comportamento.

A etapa de transposição revelou-se como uma oportunidade para o desenvolvimento da criatividade utilizando recursos digitais. Pela primeira vez as crianças puderam perceber que suas ideias, inicialmente desenhadas em papel, tornavam-se algo executável num aparelho móvel. O conceito de como se cria um jogo, desta forma, vai se transformando, e os alunos compreendem que é necessário haver um planejamento para que as ideias funcionem efetivamente. Novamente o processo criativo de Vigotski se revela nas dissociações e associações necessárias para a criação do jogo, e na elaboração conceitual construída acerca do próprio processo de design.

\subsubsection{Etapa de criação de jogos digitais}

As três primeiras etapas buscaram construir um arcabouço conceitual para as crianças sobre jogos digitais, bem como promover o trabalho coletivo e colaborativo, necessários à criação de um novo jogo digital a ser proposto pelo grupo. Elas preparam o terreno para que as crianças estivessem engajadas, seguras, e compreendessem os principais elementos que compõem um jogo digital. A partir daí, inicia-se a etapa mais longa do processo, que na pesquisa teve a duração de 15 sessões, em que um conjunto de subprocessos irão conduzir o grupo a elaboração complexa de um jogo digital.

A etapa de criação de jogos digitais, portanto, consiste em aplicar técnicas de desenvolvimento de jogos digitais, tais como brainstorms, ideia cards, dentre outros, na especificação de um jogo digital com as crianças, mediadas pelos educadores e acadêmicos. A implementação, conduzida por acadêmicos com a participação das crianças, propõe que o processo criativo não se limite em função dos conhecimentos necessários a implementação programação -, tampouco a ferramentas de autoria que estabelecem gêneros específicos de jogos. A temática para o jogo é livre, emergindo das próprias ideias das crianças, porém nada impede que o professor conduza as atividades com objetivo de aprendizagem de algum conteúdo. Ao final, as crianças deverão poder jogar o jogo por elas criado em conjunto com os acadêmicos. 
A etapa de Criação de jogos digitais apoia-se nas propostas de Moser (2015) e Novak (2011) e é composta pelas fases de Conceito, Design, Desenvolvimento e Avaliação, paralelamente aplica-se a atividade de Reconstituição do processo (Figura 4). Essas são descritas a seguir.

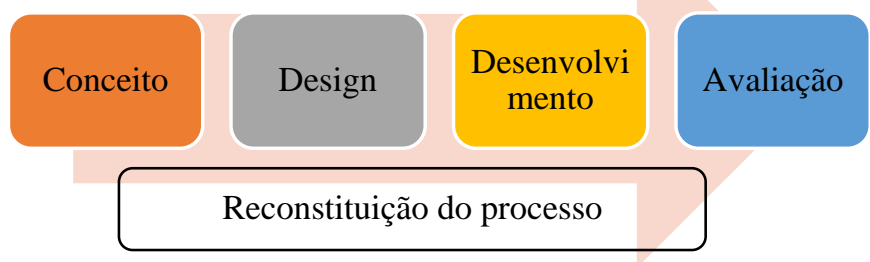

Figura 4: Subprocesso de Criação de jogos digitais.

Fonte: adaptado de Alves (2017)

A reconstituição do processo visa a retomada das atividades desenvolvidas em cada etapa do framework e a reflexão sobre o que foi aprendido. Os educadores conduzem o grupo no sentido de avaliarem os conceitos construídos, as produções e as discussões geradas e como estas serão utilizadas nas etapas vindouras. A reconstituição do processo ocorreu de forma concomitante a todas as fases do processo, por meio da elaboração de um cartaz sob forma de linha do tempo, no qual eram anexadas imagens e palavras-chave acerca das atividades realizadas. Estas foram importantes para que as crianças refletissem sobre o que haviam feito: Leonardo compreende que é necessário entender o que é um jogo para poder criar outro, e pondera "A gente joga, olha bem, vê o que tem que botar...”, referindo-se ao processo de criação; Vitória quando questionada sobre o que aprendeu afirma "aprendemos a fazer jogos”; Raphael concorda, acenando com a cabeça, quando perguntado se aprendeu a fazer um jogo. A atividade de retrospectiva permitiu às crianças refletirem sobre o que haviam feito, dando sentido a sequência de atividades realizadas até então. Isso é particularmente importante quando se desenvolve atividades com crianças com deficiência intelectual, pois favorece a consciência sobre os conceitos, conforme explica Vigotski:

\begin{abstract}
A criança adquire consciência dos seus conceitos espontâneos relativamente tarde; a capacidade de defini-los por meio de palavras, de operar com eles à vontade, aparece muito tempo depois de ter adquirido os conceitos. Ela possui o conceito (isto é, conhece o objeto ao qual o conceito se refere), mas não está consciente do seu próprio ato de pensamento. O desenvolvimento de um conceito científico, por outro lado, geralmente começa com sua definição verbal e com sua aplicação em operações não espontâneas ao operar com o próprio conceito, cuja existência na mente da criança tem início a um nível que só posteriormente será atingido pelos conceitos espontâneos. (Vigotski, 2008, pp. 134-135)
\end{abstract}

A fase de conceito tem por objetivo definir os principais parâmetros do jogo a ser construído. A equipe define o público-alvo do jogo, sua aplicação (educação, entretenimento), plataforma (computador, tablet), gênero (ação, aventura, puzzle). Também se definem os elementos que comporão o jogo, tais como, cenários, principais personagens, mecânica básica.

A técnica $w$-questions cards, que visa apresentar cartões com as questões: quem, quando, o quê, onde, porquê para promover a discussão e o debate sobre o jogo (Moser, 2015, pp. 87-89), delimitou alguns parâmetros para a criação do jogo, como público-alvo, equipamento alvo, motivação para o jogo, entre outros, delineando os conceitos que foram adotados na concepção do jogo. Schuytema (2013, p. 12) elucida que esta etapa do desenvolvimento de jogos é "um momento para discussões, brainstorms e avaliação de games concorrentes”. Assim, as crianças também avaliaram jogos similares para extrair elementos para o novo jogo. O grupo optou por utilizar a história criada na etapa de Envolvimento como roteiro para a criação do jogo digital, por este motivo, o jogo teve como temática a utilização de lixos recicláveis para criar brinquedos. 
Na definição dos conceitos básicos do jogo optou-se por utilizar a técnica de cartões, nos quais cada participante desenhou ou escreveu uma ideia. A avaliação das ideias foi realizada por meio da adaptação de uma matriz de Baxter (Baxter, 2000). Para cada jogo proposto (disposto nas linhas da matriz), avaliaram-se diversos critérios acerca da ideia (dispostos nas colunas), verificando se atende aos requisitos previamente propostos, tais como público-alvo, plataforma, diversão. Cada membro do grupo (crianças, educadores e acadêmicos) avaliou individualmente e depois fez-se uma compilação dessas avaliações para chegar-se a proposta de jogo escolhida. A vantagem dessa técnica é que todas as ideias são consideradas e chega-se de forma democrática ao conceito do jogo.

Intensas negociações e o trabalho coletivo e colaborativo foram necessários para definir um jogo que fosse de autoria de todos. Aqui a mediação novamente foi fundamental para que as ideias e opiniões fossem respeitadas e discutidas entre todos. Os conceitos sobre jogos digitais foram se consolidando a medida em que o grupo definia mecânicas e estratégias para o jogo.

Destaca-se nessa fase a espontaneidade com que surgiram desenhos das crianças para definir o level design do jogo. A partir das ideias iniciais de Leonardo para o jogo, como pegar moedas ao longo de uma plataforma, Vitoria e Raphael contribuíram com suas ideias. Raphael desenhou a personagem antes e depois de pegar as moedas, e definiu um roteiro do que aconteceria, com as crianças aparecendo e percebendo que as moedas foram roubadas. A Figura 5 apresenta Raphael explicando seu desenho. Vitoria também elabora desenhos, baseados no de Raphael, acrescentando elementos diferentes, como "brinquedos assustadores". Vigotski descreve semelhante experiência vivenciada por Tolstoi na produção literária coletiva com crianças, a qual transfiro para o desenvolvimento de jogos, e conclui:

A compreensão adequada e científica da educação não consiste em incutir artificialmente nas crianças os ideais, sentimentos ou critérios que lhes sejam completamente alheios. A verdadeira educação consiste em despertar na criança aquilo que ela já tem em si, ajudála a desenvolvê-lo e orientar seu desenvolvimento em determinada direção. (Vigotski, 2014, p. 61)

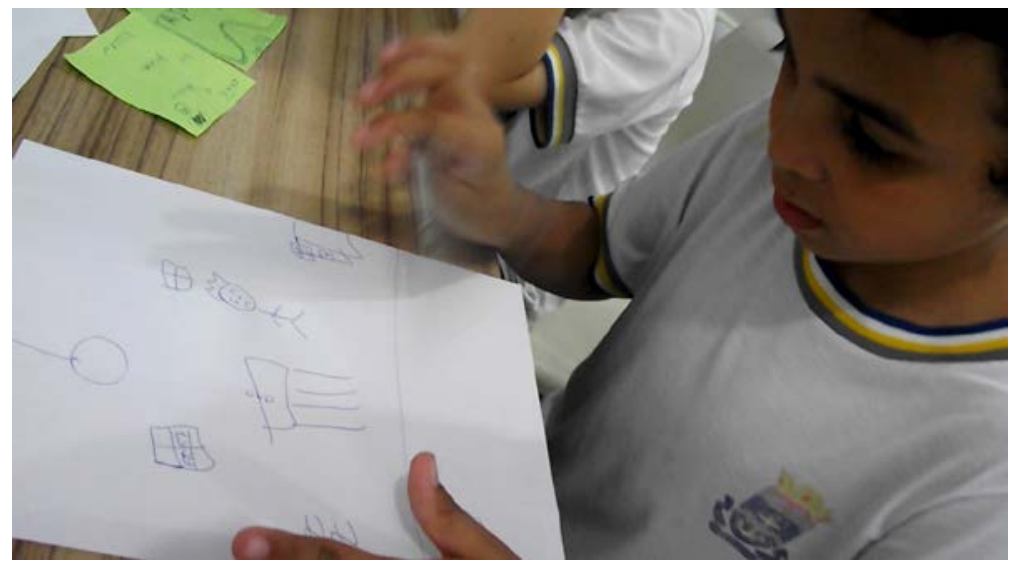

Figura 5: Raphael desenha e explica o jogo baseando-se na ideia de Leonardo.

Fonte: Alves (2017)

A fase de design envolveu atividades de prototipação, com destaque do protótipo experimental, em que as crianças avaliaram a mecânica do jogo por meio de simulação. A ideia do protótipo experimental surgiu a partir das próprias crianças, quando Leonardo, observando Vitória gesticulando e "fingindo" jogar, sugeriu que fizéssemos um teatro sobre o jogo. A técnica de "Protótipo Experimental” é uma alternativa que permite às crianças validarem as ideias do jogo por meio de uma simulação física, tal como um teatro ou brincadeira (Buchenau e Suri, 2000 apud Moser, 2015, p. 30-31). Interpretando os personagens ou agindo como se fossem o "jogo", as 
crianças verificam se o que foi idealizado irá funcionar na prática, identificam dificuldades ou problemas e propõem melhorias. Esta técnica facilita a compreensão acerca do jogo, notadamente para crianças que têm dificuldade de abstração, pois o jogo se torna "físico" ou "real”. Espera-se que deste concreto, elas consigam fazer o caminho para a abstração.

Outras atividades da fase do design incluíram os desenhos de esquemas para representar o level design da fase e minigame. Também foram feitos protótipos de personagens por meio de desenhos e tridimensionais (com sucatas). Na criação de personagens a atividade de design experimental realizada anteriormente favoreceu a compreensão das crianças. Vitória, por exemplo, repetiu a encenação de coletar os "lixos" no chão - mecânica definida para o jogo - e a partir daí conseguiu construir uma sereia, a qual transpôs para o papel por meio de um desenho. Os protótipos foram criados digitalmente por uma designer, que buscou a fidelidade com as propostas das crianças. Observa-se o processo de criação em que a criança primeiramente criou uma sereia com caixa de giz, bobs, EVA, depois fez um desenho (Figura 6(a)). A partir disso, a designer elaborou a versão digital da sereia (Figura 6(b)) e os assets para sua montagem no jogo.

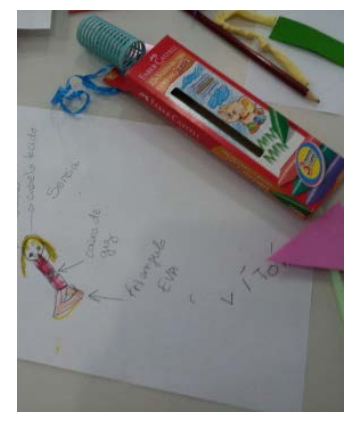

(a) Sereia criada com sucatas

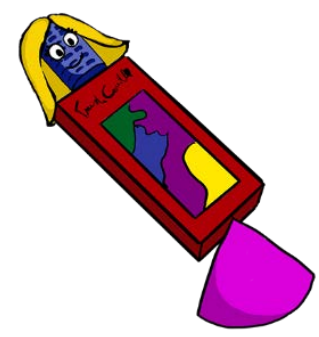

(b) Versão digital da Sereia

Figura 6: Criação de personagens do jogo.

Fonte: Alves (2017)

A fase de desenvolvimento consistiu na implementação do jogo digital "Os brinquedos que criam vida”, a partir das definições anteriores. As crianças acompanharam as versões do jogo desenvolvido pelo acadêmico de computação, inclusive reconhecendo a ferramenta de desenvolvimento e a linguagem de programação utilizada. Elas fizeram experimentos, alterando valores de variáveis e observando os resultados obtidos no jogo. Isso permitiu que compreendessem a forma como nos "comunicamos" com os computadores, ou seja, a linguagem que ele entende. Esta atividade foi importante para que as crianças percebessem que o jogo não aparece do papel de forma instantânea no computador.

A fase de avaliação foi composta por inúmeros testes do jogo criado. Além de apontar eventuais falhas, esta permitiu refletir se estava presente no jogo implementado aquilo que foi planejado: uma plataforma por onde a personagem caminha e coleta lixos; cria brinquedos por meio de minigames e no final enfrenta o boss "Lixeira". A Figura 7 (a) apresenta uma das crianças testando o jogo e a Figura 7 (b) uma das cenas do jogo, em que o jogador deve derrotar o boss . 


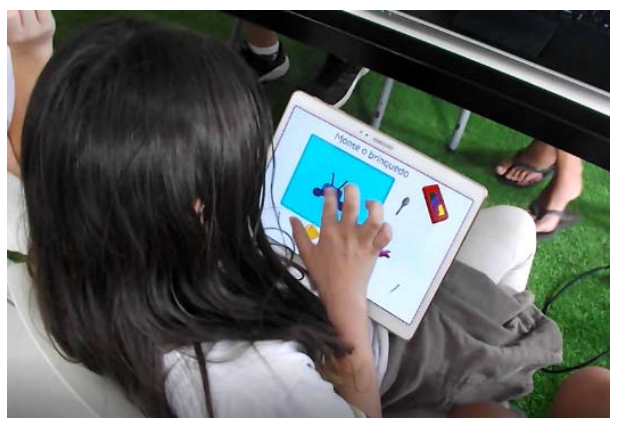

(a) Avaliação do jogo

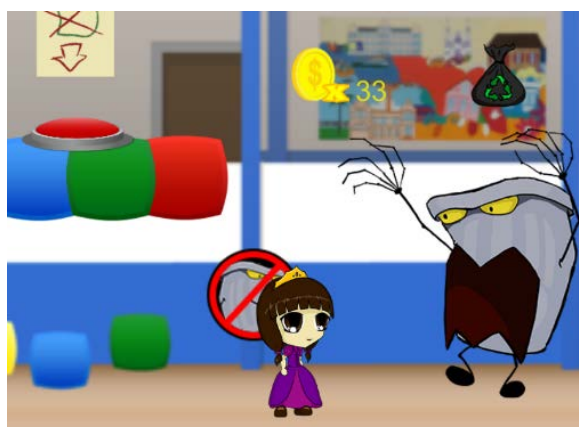

(b) Cena final do jogo

Figura 7: O jogo "Os Brinquedos que criam vida”.

Fonte: Alves (2017)

Questionadas novamente, ao final do projeto, “como se desenvolve um jogo digital”, a resposta de uma das meninas se destaca: "Eu morro na frente dele", constatando o quanto foi complexo desenvolver o jogo. O conceito de criar um jogo, ao longo de todo o projeto, foi se modificando. Antes, para uma, consistia em "baixar" da internet, para outro "copiar num CD”. A medida em que foram vivenciando as diferentes etapas do processo e construindo o jogo, as crianças passaram a compreender aquilo que é necessário "tem que desenhar, criar o cenário, bonecos”, “testar!”. Na expressão da emoção de um dos meninos “eh! Passei passei passei passei!” ao finalmente derrotar o boss, ressalta-se a importância no processo de concluir o jogo com sucesso, pois isso efetivamente encerra o processo criativo, a cristalização.

\section{Considerações finais}

Adotar o game design como proposta pedagógica vem ao encontro do uso de tecnologias na educação não mais somente como ferramenta, mas também como conteúdo ou objeto de ensino. Significa rever o uso da tecnologia como software para ensinar, remetendo a um novo paradigma tecnológico, no qual adotam-se os conhecimentos sobre os próprios conhecimentos. Nesta abordagem, o estudante é o protagonista do processo de criação de jogos digitais, e não somente usuário.

O trabalho diferencia-se de outros processos metodológicos em diversos aspectos, destacando-se: a complexidade e riqueza de atividades proporcionadas pelo design de games, possibilitando um compartilhamento significativo de ideias e conceitos; a aplicação a um grupo heterogêneo de crianças, com diferentes níveis intelectuais, favorecendo a inclusão escolar de crianças com deficiência intelectual; a reconstituição do processo por meio da linha do tempo, permitindo às crianças refletirem sobre as tarefas e compreenderem o percurso realizado para alcançar seus objetivos; as etapas iniciais de Envolvimento, Experiência e Transposição, que possibilitam a elaboração de conceitos acerca de jogos e seu desenvolvimento, estabelecendo o arcabouço necessário para a criação do jogo digital; a flexibilidade de adequação das técnicas propostas, passíveis de revisão no decorrer das atividades, conferindo ao educador uma liberdade para adaptar o processo de acordo com as necessidades dos estudantes; o foco no processo criativo, favorecendo o desenvolvimento das funções psicológicas superiores por meio de atividades prazerosas e desafiadoras.

O processo criativo definido por Vigotski é a chave do framework aqui apresentado. A cristalização por meio dos processos de dissociação e associação se evidencia em diversos momentos: a história elaborada a partir de objetos criados com sucatas; a criação de jogos com o Inventame a partir dos desenhos e dos experimentos anteriores; o design experimental concebido 
a partir de ações espontâneas das crianças; o projeto de level design construído a partir de ideias e da análise de jogos similares; dentre outros. O "tormento da criação" descrito por Vigotski foi efetivamente provocado pelo processo vivenciado pelo grupo na intervenção na escola. Colocado como o "problema” a ser resolvido - criar um jogo digital - foi necessário que novos conhecimentos viessem à tona para permitir as crianças apresentarem soluções. Nós não as ensinamos desenhar, escrever, atuar, mas foram justamente esses conhecimentos prévios que permitiram contextualizar suas criações na perspectiva da criação do jogo. As crianças já conheciam jogos, tanto analógicos como digitais, mas a desconstrução e reconstrução desse conceito foram necessárias à atividade de design do novo jogo.

Os resultados obtidos alinham-se com as diretrizes de Börjesson et al., notadamente nas atividades realizadas na fase de Envolvimento, que permitiram conhecer as crianças de forma gradual e promoveram o engajamento e a colaboração entre os pares; na flexibilidade do método que permitiu a adaptação conforme as demandas e respostas dos alunos, favorecendo o estímulo às diferentes competências, de acordo com o potencial e necessidades das crianças; a participação de pessoas de diferentes níveis de conhecimento - estudantes do ensino básico, estudantes de graduação, professoras/pesquisadoras das áreas de computação e pedagogia - que enriqueceram a experiência e favoreceram atuar na zona de desenvolvimento proximal das crianças, e portanto favorecer o desenvolvimento intelectual dos participantes.

A mediação das pesquisadoras procurando envolver todas as crianças em todas as tarefas, possibilitou a participação dos estudantes com deficiência intelectual, que talvez em outros contextos ficassem excluídos. A percepção sobre certas dificuldades das crianças conduziu a estratégias para estimular o trabalho colaborativo. Em alguns momentos torna-se difícil para as crianças, mais desenvolvidas intelectualmente, realizarem atividades com as outras, o que ficou claro em diferentes momentos, entretanto, outras capacidades das crianças com deficiência vieram à tona no processo, percebidas pelos próprios colegas, conforme destaca Leonardo "ô que legal que o Rapha fez professora!”, referindo-se ao desenho de Raphael. Assim, independentemente de suas deficiências, todas as crianças participaram de forma igualitária. Nesse sentido, vale salientar a mediação entre as crianças, que inúmeras vezes se ajudavam na realização das atividades.

A produção de um jogo digital por meio do framework "Eu fiz meu game” mostrou-se uma abordagem promissora no sentido de promover a coletividade, a colaboração, a experiência, a mediação simbólica, a imaginação e a criatividade. O eixo de todo o projeto foi o novo jogo digital, em torno do qual todas as atividades e criações foram desenvolvidas. Do ponto de vista pedagógico, o processo deve ser mais importante que o produto final - o jogo - no entanto deuse ênfase especial para que este atingisse o grau de qualidade que permitisse às crianças sentiremse autoras orgulhosas dos resultados. Isto foi particularmente evidenciado pela publicação do jogo na Google Play, a pedido das crianças. Considera-se, dessa forma, que a pesquisa contribuiu para ampliar as possibilidades de aprendizagem de todas as crianças, especialmente aquelas com deficiência intelectual, as quais viveram a experiência de interação e de criação em atividades de jogos, ampliando seu universo de imaginação e materialização de sua criatividade.

Do ponto de vista da aplicação do framework em outros contextos escolares, temos como trabalhos futuros novas intervenções a serem feitas no sentido de avaliar outras possibilidades, como grupos maiores de crianças, por exemplo. Outro aspecto que pode ser explorado é implementar o framework com grupos heterogêneos em diferentes aspectos do utilizado nesta pesquisa, como crianças de faixas etárias distintas e frequentando diferentes classes na escola (ano escolar), assim como crianças com outras deficiências, diferentes classes sociais ou econômicas. Essas diferenças podem trazer novos desafios a implementação do framework e a articulação de estratégias que precisarão ser adotadas para bem conduzir o projeto. Novos resultados, nesse sentido, irão enriquecer a pesquisa e trazer outras possibilidades, seja em termos de 
desenvolvimento cognitivo dos envolvidos, seja na questão da inclusão escolar de alunos com deficiência.

\section{Agradecimentos}

Os autores agradecem à Capes e ao CNPq pelo financiamento da pesquisa, à Secretaria de Educação do Munícipio de Itajaí, à direção e professores da Escola Gaspar da Costa Morais, e às crianças envolvidas na pesquisa e seus responsáveis, sem os quais este trabalho não se viabilizaria.

\section{Referências}

Alves, A. G. (2017). Eu fiz meu game: um framework para criação de jogos digitais por crianças. Itajaí: 283 f. Tese (Doutorado) - Curso de Programa de Pós-graduação em Educação, Universidade do Vale do Itajaí.

Alves, A. G., Cathcart, K. P., \& Hostins, R. L. (2014). Jogos digitais acessíveis como instrumento de elaboração conceitual na perspectiva da inclusão escolar. VI Congresso Brasileiro de Educação Especial, IX Encontro Nacional dos Pesquisadores da Educação Especial. São Carlos. Acesso em 26 de 1 de 2016, disponível em http://proceedings.galoa.com.br/cbee/trabalhos/jogos_digitais_acessiveis_como_instrum ento_de_elaboracao_conceitual_na_perspectiva_da_inclusao. [GS SEARCH]

Alves, A. G., Hostins, R. L., \& Raabe, A. A. (2017). Eu fiz meu game: um framework para desenvolvimento de jogos por crianças. Anais dos Workshops do Congresso Brasileiro de Informática na Educação(VI Congresso Brasileiro de Informática na Educação). Doi: http://dx.doi.org/10.5753/cbie.wcbie.2017.2 [GS SEARCH]

Amiel, T., \& Reeves, T. C. (2008). Design-Based Research and Educational Technology: Rethinking Technology and the Research Agenda. Journal of Educational Technology \& Society, 11(4), pp. 29-40. [GS SEARCH]

Bamberg, M. (2012). NARRATIVE ANALYSIS. Em U.-D. Reips, \& H. Cooper (Ed.), APA handbook of research methods in psychology: Research designs: Quantitative, qualitative, neuropsychological, and biological (Vol. 2, pp. 291-310). [GS SEARCH]

Baumgartner, E., Bell, P., Hoadley, C., Hsi, S., Joseph, D., Orrill, C., . . . Tabak, I. (January/February de 2003). Design-based research: an emerging paradigm for educational inquiry. Educational Researcher, 32(1), pp. 5-8. Acesso em 17 de 09 de 2016. Doi: https://doi.org/10.3102\%2F0013189X032001005 [GS SEARCH]

Baxter, M. (2000). Projeto de Produto. São Paulo: Edgard Blücher.

Benton, L., Johnson, H., Ashwin, E., Brosnan, M., \& Grawemeyer, B. (5 de 2012). Developing IDEAS: Supporting children with autism within a participatory design team. Proceedings of the 2012 ACM annual conference on Human Factors in Computing Systems - CHI '12. doi: http://doi.org/10.1145/2207676.2208650 [GS SEARCH]

BigStar Brinquedos. (2016). Novidades e Produtos. Acesso em 26 de 1 de 2016, disponível em BigStar: http://www.bigstarbrinquedos.com.br/

Börjesson, P., Barendregt, W., Eriksson, E., \& Torgersson, O. (2015). Designing technology for and with developmentally diverse children - A Systematic Literature Review. Proceedings 
of the 14th International Conference on Interaction Design and Children - IDC '15, pp. 79-88. doi: http://doi.org/10.1145/2771839.2771848 [GS SEARCH]

De Paula, B. H., Valente, J. A., \& Hildebrand, H. R. (Janeiro/Março de 2016). Criar para aprender: Discutindo o potencial da criação de jogos digitais como estratégia educacional. (F. d. Mota, Ed.) TECNOLOGIA EDUCACIONAL - Ano LIV - 212 Janeiro / Março - 2016 Revista da Associação Brasileira de Tecnologia Educacional, p. 6-18., Ano LIV - 212, pp. 6-18. Acesso em 28 de 01 de 2017, disponível em http://www.abtbr.org.br/images/rte/212.pdf [GS SEARCH]

Disney Entertainment. (2016). Where's my water. Acesso em 26 de 1 de 2016, disponível em Disney: http://www.disney.com.br/mobile/wheresmywater/jogos.html

Foss, E., Guha, M. L., Papadatos, P., Clegg, T., Yip, J., \& Walsh, G. (01 de 9 de 2013). Cooperative Inquiry Extended: Creating Technology with Middle School Students with Learning Differences. Journal of Special Education Technology, 28(3), 33 - 46. doi: http://doi.org/10.1177/016264341302800303 [GS SEARCH]

Herrington, J., Mckenney, S., Reeves, T. C., \& Oliver, R. (2007). Design-based research and doctoral students: Guidelines for preparing a dissertation proposal. (C. M. Seale, Ed.) Proceedings of World Conference on Educational Multimedia, Hypermedia and Telecommunications, pp. 4089-4097. Fonte: http://ro.ecu.edu.au/ecuworks/1612/ [GS SEARCH]

Ibáñez, J. (2015). Inventame. Acesso em 09 de 02 de 2015, disponível em Inventame: http://inventame.org/

Li, Q. (2014). Learning through digital game design and building in a participatory culture: an enactivist approach (Vol. 14). New York: Peter Lang.

Marchetti, E., \& Valente, A. (2015). Learning via Game Design: From Digital to Card Games and Back Again. The Electronic Journal of e-Learning, 13(3), pp. 167-18. Acesso em 1 de 10 de 2016, disponível em www.ejel.org [GS SEARCH]

Modesto, F. A., \& Mustaro, P. N. (2014). Revisão Sistemática para estudo de Interação CriançaComputador. $3^{\circ}$ Congresso Brasileiro de Informática na Educação (CBIE 2014) Workshops (WCBIE 2014), (pp. 554-563). Dourados. Acesso em 21 de 1 de 2016. DOI : http://dx.doi.org/10.5753/cbie.wcbie.2014.554 [GS SEARCH]

Moll, L. C. (1996). Vygotsky e a educação: implicações pedagógicas da psicologia sóciohistórica. Porto Alegre: Artes Médicas.

Moser, C. (2015). Child-Centered Game Development. Salzburg, Áustria.

Muller, M. J., \& Druin, A. (2010). Participatory design: the third space in HCI. Relatório Técnico, IBM. Acesso em 20 de 1 de 2016, disponível em http://www.watson.ibm.com/cambridge/Technical_Reports/2010/TR2010.10\%20Partici patory\%20Design\%20The\%20Third\%20Space\%20in\%20HCI.pdf

Novak, J. (2011). Desenvolvimento de Games (2 ed.). São Paulo: Cengage Learning.

Oliveira, M. K. (1995). Vygotsky: aprendizado e desenvolvimento - um processo sócio-histórico (2 ed.). São Paulo: Scipione.

Prensky, M. (2012). Aprendizagem baseada em jogos digitais (1 ed.). São Paulo: Senac São Paulo. 
Read, C. J., \& Markopoulos, P. (1 de 2013). Child-computer interaction. International Journal of Child-Computer Interaction, 1, pp. 2-6. doi: http://doi.org/10.1016/j.ijcci.2012.09.001 [GS SEARCH]

Schuytema, P. (2013). Design de Games: uma abordagem prática. São Paulo: Cengage Learning.

Silva, C., Hostins, R. C., \& Mendes, R. d. (set./dez. de 2016). O lugar do Atendimento Educacional Especializado nas práticas culturais de escolarização em contextos de inclusão escolar. Revista Linhas, 17(35), pp. 10-29. http://www.revistas.udesc.br/index.php/linhas/article/view/1984723817352016010/pdf 148 [GS SEARCH]

Vigotski, L. S. (1997). Obras Escogidas V: Fundamentos da defectología. Madrid: Visor Distribuiciones.

Vigotski, L. S. (2007). A formação social da mente: o desenvolvimento dos processos psicológicos superiores (7 ed.). (J. C. Neto, L. S. Barreto, \& S. C. Afeche, Trads.) São Paulo: Martins Fontes.

Vigotski, L. S. (2008). Pensamento e linguagem (4 ed.). São Paulo: Martins Fontes.

Vigotski, L. S. (2010). Quarta Aula: a questão do meio na pedologia. Psicologia USP, 21(4), pp. 681-701.

Vigotski, L. S. (2014). Imaginação e criatividade na infância. (J. P. Fróis, Trad.) São Paulo: WMF Martins Fontes.

Wang, F., \& Haffanin, M. J. (2005). Design-based research and technology-enhanced learning environments. Educational technology research and development, 5, pp. 1-6. doi: http://doi.org/10.1007/BF02504682 [GS SEARCH] 